\title{
Analisis Tingkat Kepuasan Pasien BPJS Pada Pelayanan Kefarmasian Di Apotek Klinik SATKES PUSDOKKES MABES POLRI
}

\author{
Analysis Of BPJS Patient Satisfication Level In Pharmaceutical Services In \\ Pharmacy SATKES PUSDOKKES MABES POLRI \\ Okpri Meila ${ }^{1}$, Jenny Pontoan ${ }^{2}$, Eddy Zizwanto ${ }^{2,3}$ \\ ${ }^{1}$ Juruan Farmasi, Fakultas MIPA, Universitas Syiah Kuala, Banda Aceh \\ ${ }^{2}$ Fakultas Farmasi, Institut Sains dan Teknologi Nasional, Srengseng Aceh \\ ${ }^{3}$ Poliklinik SatKes Pusdokkes Mabes Polri Jakarta Selatan \\ korespondensi: okprimeila@unsyiah.ac.id
}

\begin{abstract}
Service satisfaction is achieved if what the patient gets exceeds what is expected. This study to determine the level of BPJS patient satisfaction and dimensions affect the level of satisfaction with pharmaceutical services provided in Drugstore Clinic Satkes Pusdokkes Headquarter Police. This reasearch was conducted the data of patients who were treated and carried out in cross sectional, by distribution questioner and analyzed descriptive. Reasearch subjects were teken by quota sampling technique. The level of satisfaction of this study was measured based on five dimensions of service quality and analyzed using percentase and likert scalet. The results of the showed that patients who were treated at the Drugstore Clinic Satkes Pusdokkes Headquarter Police were satisfied with the services provided by the services provided
\end{abstract}

Keyword : Satisfaction level, pharmaceutical services, BPJS

\section{PENDAHULUAN}

Pelayanan kefarmasian adalah suatu pelayanan langsung dan bertanggung jawab kepada pasien yang berkaitan dengan sediaan farmasi dengan maksud mencapai hasil yang pasti untuk meningkatkan mutu kehidupan pasien. Salah satu bentuk standar pelayanan kefarmasian di apotek, sebagaimana yang diatur dalam Peraturan Menteri Kesehatan RI nomor 73 tahun 2016. Sehingga pelayanan kefarmasian terutama di apotek sangat dibutuhkan dalam meningkatkan kesehatan terhadap masyarakat.

Apotek salah satu sarana kesehatan dalam pelayanan kefarmasian dimana tempat dilakukan praktik kefarmasian oleh Apoteker. Pelayanan kefarmasian di apotek telah mengalami perubahan yang semula berfokus pada pengelola obat (drug oriented) berkembang menjadi pelayanan komphrensif, meliputi pengelolaan sediaan farmasi, alat kesehatan, dan bahan medis habis pakai serta pelayanan farmasi klinik, meliputi; pengkajian dan pelayanan resep, dispensing, Pelayanan Informasi Obat (PIO), konseling, pelayanan kefarmasian di rumah (home pharmacy care), Pemantauan Terapi Obat (PTO), dan Monitoring Efek Samping Obat (MESO). Kegiatan tersebut harus didukung oleh sumber daya manusia, sarana dan prasarana. Keberhasilan suatu pelayanan kefarmasian sangat erat dengan tingkat kepuasan pasien. (Permenkes Nomor 73, 2016).

Dalam menghadapi persaingan yang semakin ketat hal yang utama diperhatikan oleh suatu pelayanan kefarmasian khususnya di apotek adalah kepuasan pasien agar dapat setia atau bertahan. Kepuasan pasien didapatkan jika apa yang dirasakan pasien dari suatu pelayanan sebanding atau lebih besar dari harapan mereka. Bila kinerja dibawah harapan, pelanggan akan sangat kecewa, sebaliknya bila kinerja sesuai harapan, pelanggan akan sangat puas. Faktorfaktor yang mempengaruhi tingkat kepuasan pasien diantaranya; kualitas pelayanan, faktor emosional, harga dan biaya. kualitas pelayanan memiliki lima dimensi, yaitu; tangibility (bukti fisik), realibility (kehandalan), responsiveness 
(daya tanggap), assurance (jaminan), dan empathy (empati) (Yulia dkk., 2016).

Salah satu program pemerintah untuk memberikan pelayanan kesehatan adalah dengan mengeluarkan Undang-Undang Nomor 40 tahun 2004 tentang Sistem Jaminan Sosial Nasional (SJSN). Dalam Undang-Undang tersebut jaminan sosial wajib bagi seluruh rakyat Indonesia dan terhitung mulai 1 Januari 2014 untuk meningkatkan pelayanan kesehatan dengan mengaktifkan Program Jaminan Kesehatan Nasional melalui suatu Badan Penyelenggara Jaminan Sosial Kesehatan (BPJS Kesehatan). BPJS berperan dalam memberikan pelayanan kompherensif adil dan merata kepada seluruh warga negara Indonesia yang sifatnya berjenjang. Dalam implementasinya BPJS menerapkan prinsip manage care yang terdapat 4 pilar, yaitu promotif dan preventif (Faskes tingkat pertama atau klinik dan puskesmas) dan kuratif dan rehabilitatif (Faskes tingkat lanjutan atau rumah sakit). Sehingga lebih difokuskan pada pelayanan kesehatan Faskes tingkat pertama (FKTP) atau Faskes Primer seperti; puskesmas, klinik dan dokter praktik yang merupakan gerbang utama pada peserta BPJS yang akan mengakses pelayan kesehatan. Selain itu BPJS berperan penting dalam meregulasi sistem pelayanan kesehatan khususnya Faskes tingkat pertama, terutama dalam hal pemberian pelayanan kefarmasian. Dengan pelayanan kefarmasian yang optimal diharapkan pasien atau konsumen mendapatkan kepuasan terhadap fasilitas yang diberikan.

Klinik Satkes Pusdokkes Mabes Polri merupakan Klinik Fasilitas Kesehatan Pertama (FKTP) milik instansi Mabes Polri yang memberikan pelayanan kesehatan dalam bentuk pemeriksaan, pengobatan dan perawatan terhadap anggota Polri, PNS dan keluarganya serta dukungan kesehatan dalam rangka operasional Kepolisian, namun juga memberikan pelayanan kepada masyarakat umum. Dari data jumlah pasien rawat jalan Klinik Satkes Pusdokkes mabes Polri tahun 2017 sebanyak 7.436 pasien, sedangkan pada tahun 2018 jumlahnya sebanyak 6.484 pasien. Hal ini menunjukkan adanya penurunan pasien rawat jalan sebanyak $12,8 \%$. Selain itu, jumlah pasien yang menerima resep atau menebus resep di Apotek tahun 2017 sebanyak 6.787 pasien, sedangkan pada tahun 2018 sebanyak 5.347 pasien. Sehingga mengalami penurunan sebanyak $21,2 \%$.

Berdasarkan uraian diatas, maka perlu dilakukan penelitian terhadap pelayanan kefarmasian "Tentang Analisis Tingkat Kepuasan Pasien BPJS Terhadap Pelayanan Kefarmasian Di Apotek Klinik Satkes Pusdokkes Mabes Polri”, sehingga diketahui unsur yang harus dipertahankan dan diperbaiki oleh Apotek klinik Satkes agar dapat lebih meningkatkan kualitas pelayanannya terutama di Apotek.

\section{II.TINJAUAN PUSTAKA}

Kepuasan dapat diartikan sebagai perasaan puas, rasa senang dan kelegaan seseorang dikarenakan mengkonsumsi suatu produk atau jasa untuk mendapatkan pelayanan atau jasa. Tingkat kepuasan merupakan perbedaan antara kinerja yang dirasakan dengan harapan. Apabila kinerja dibawah harapan, maka pelanggan akan sangat kecewa. Bila kinerja sesuai harapan, maka pelanggan akan sangat puas (Purba, 2012).

Salah satu cara untuk mengukur kepuasan pelanggan adalah model Servqual (Service Quality) dengan cara membuat survey penilaian kepuasan pelanggan secara komprehensif bagi pelayanan di bidang barang dan jasa yang mengutamakan aspek pelayanan. Analisis kualitas kepuasan pelanggan dilakukan berdasarkan lima dimensi kualitas layanan, yaitu:

1. Kehandalan (reability), yaitu kemampuan memberikan pelayanan sesuai dengan yang dijanjikan secara akurat dan terpercaya. Kinerja harus sesuai dengan harapan pelanggan seperti; ketepatan waktu, pelayanan yang sama untuk semua pasien tanpa kesalahan, sikap yang simpatik dan dengan akurasi yang tinggi.

2. Daya Tanggap (responsiveness), yaitu kebijakan untuk membantu dan memberikan pelayanan yang cepat dan tepat kepada pasien, dengan penyampaian informasi yang jelas. Membiarkan pasien menunggu tanpa ada alasan yang jelas menyebabkan persepsi negatif dalam kualitas pelayanan.

3. Jaminan (assurance), yaitu pengetahuan, kesopan santunan dan kemampuan para pegawai 
menumbuhkan rasa percaya kepada pasien. Hal ini meliputi; komunikasi (communication), kredibilitas (credibility), keamanan (security), kompetensi (competence), dan sopan santun (courtesy).

4. Bukti langsung (tangibles), yaitu kemampuan menunjukkan eksistensinya kepada pihak eksternal. Penampilan dan kemampuan sarana dan prasarana fisik yang dapat diandalkan merupakan bukti nyata dari pelayanan yang diberikan oleh pemberi jasa. Contoh; gedung, gudang, perlengkapan dan teknologi kedokteran yang digunakan serta penampilan pegawainya.

5. Empati (empathy), yaitu memberikan perhatian yang tulus dan bersifat individual atau pribadi yang diberikan kepada pelanggan dengan berupaya memahami keinginan pasien. Diharapakan memiliki pengetahuan dan pengertian tentang pelanggan secara spesifik, serta memiliki waktu pengoperasian yang nyaman bagi pasien.

Selain kualitas layanan, kepuasan pelanggan juga dipengaruhi oleh beberapa faktor. Faktor-faktor yang mempengaruhi kepuasan pasien terdiri atas dua aspek, yakni aspek pelanggan dan aspek pelayanan kesehatan;

1. Aspek pelanggan dipengaruhi oleh faktor karakteristik dari individu pasien, diantaranya:

a. Usia, merupakan salah satu indikator dalam menentukan penilaian seseorang. Seseorang. Berdasarkan usia dapat menentukan penilaian pasien karena pengetahuan, pandangan dan pengalaman masa lalu akan mempengaruhi penilaian atau persepsi seseorang dalam mendapatkan pelayanan yang memuaskan terhadap sesuatu (Armansyah S., 2014) .

b. Jenis kelamin, dapat mempengaruhi kepuasan karena banyak beranggapan wanita dianggap lemah, tidak rasional dan kurang berpengalaman, sedangkan laki-laki dianggap sebaliknya, sehingga cenderung membutuhkan pelayanan yang lebih baik untuk mencapai kepuasan (Barata A.A., 2006).

c. Pendidikan, dapat mempengaruhi kepuasan karena dengan tingkat pendidikan yang lebih tinggi cenderung banyak menuntut atau mengkritik terhadap pelayanan yang diterimanya jika memang menurutnya kurang puas. Sebaliknya seseorang dengan tingkat pendidikan rendah, cenderung lebih banyak menerima karena tidak tahu apa yang dibutuhkannya, asal sembuh saja sudah cukup baginya (Lumenta, 1989).

d. Pekerjaan, dapat mempengaruhi kepuasan pasien terhadap pelayanan kesehatan, karena pasien yang bekerja adalah pasien yang produktif yang lebih peka terhadap keadaan sekitar yang dialami (Mathis, R.L. dan J.H. Jackson, 2011).

2. Aspek pelayanan kesehatan terdiri dari dua faktor, yaitu aspek medis, seperti tersedianya peralatan yang memadai, dan aspek non medis yang mencakup layanan petugas kesehatan, kenyamanan dan kebersihan ruang tunggu, serta biaya murah (Purba, 2012).

Untuk mengukur kepuasan kepuasan pelanggan dapat dilakukan dengan empat cara, yaitu (Tjiptono, 2005):

1. Sistem keluhan dan saran, yaitu melalui penyediaan kotak saran, customer hotlines, kartu komentar. Namun dari pengamatan empiris, cara ini kurang efektif, khususnya di klinik yang latar belakang masyarakatnya masih tradisional, artinya minimnya penggunaan kotak saran bukan indikator tingginya tingkat kepuasan pelanggan.

2. Ghostshopping, yaitu metode menggunakan cara mempekerjakan orang yang menyamar untuk bersikap atau berperan sebagai pembeli potensial, sehingga dapat melakukan pengamatan langsung. Kendalanya tidak mudah mencari orang yang mampu berperan baik dan objek yang diamati biasanya terbatas.

3. Lost customer analysis, artinya menghubungi pelanggan yang berhenti membeli atau menggunakan produk jasa pelayanan yang diberikan. Kesulitan mungkin dalam bentuk budaya rasa segan berterus terang, alamat yang kurang jelas atau jauh serta membutuhkan biaya lebih banyak. 
4. Survey kepuasan pelanggan, yaitu menggunakan kuisioner melalui angket atau wawancara, dapat dilakukan pasien menunggu di ruang tunggu atau klinik.

Kepuasan pasien akan terpenuhi bila pelayanan yang diberikan dalam suatu pelayanan klinik atau rumah sakit dirasakan telah sesuai dengan harapan pasien. Sehingga kepuasan pasien akan memberikan manfaat keuntungan dan dampak yang sangat penting bagi manajemen klinik atau rumah sakit seperti munculnya loyalitas pada pasien sehingga pasien akan datang kembali memanfaatkan jasa. Ketidakpuasan pasien terhadap pelayanan akan berdampak pada jumlah kunjungan di klinik atau rumah sakit serta mendorong pasien untuk menggunakan jasa pesaing dan pada akhirnya mengakibatkan penurunan laba (Tjiptono, 2005).

\section{III.METODE PENELITIAN}

Jenis penelitian ini menggunakan penelitian kuantitatif dengan penyampaian secara deskriptif, yaitu menggunakan data dalam bentuk angka yang bertujuan untuk mengetahui tingkat kepuasan pasien terhadap pelayanan kefarmasian. Penelitian ini menggunakan pendekatan secara cross sectional, yaitu penelitian yang menghubungkan variabel independen (variabel bebas/resiko) dengan variabel dependen (varibel terikat/efek) yang diukur atau dikumpulkan dalam waktu bersamaan. Populasi penelitian ini adalah pasien yang menebus resep di Apotek Klinik Satkes Pusdokkes Mabes Polri pada bulan Februari 2019 sebanyak 638 pasien. Jumlah sampel dalam penelitian ini menggunakan rumus Slovin sebagai berikut:

$$
n=\frac{N}{1+N \cdot e^{?}}
$$

\section{Keterangan:}

$\mathrm{n} \quad=$ ukuran sampel

$\mathrm{N}=$ ukuran populasi sebanyak 638 pasien.

$\mathrm{e}=$ nilai kritis (batas ketelitian) yang diinginkan (persen kelonggaran ketidaktelitian karena kesalahan pengambilan sampel populasi), nilai kritis dalam memilih anggota sampel yang masih dapat ditoleransi sebesar $5 \%$.
Berdasarkan rumus diatas, maka besar sampel penelitian ini adalah:

$$
\begin{aligned}
& n=\frac{638}{1+\left\{638 \times(0,05)^{2}\right\}} \\
& n=\frac{638}{1+1,595} \\
& n=245,86=246
\end{aligned}
$$

Berdasarkan hasil perhitungan dengan rumus diatas, didapatkan sampel sebanyak 246 responden. Untuk mengantisipasi terjadinya pengisian kuesioner yang drop out, maka penulis menambahkan jumlah responden sebanyak $10 \%$, sehingga didapat sampel sebanyak $246+24,6=$ $270,6 \approx 271$ responden. Teknik pengambilan sampel yang digunakan dalam penelitian ini adalah dengan cara quota sampling atau sampel quota dengan kuota sebanyak \pm 15 pasien/hari selama 19 hari.

Pengumpulan data yang digunakan dalam penelitian ini adalah dengan menggunakan data, antara lain; data primer, yaitu data yang dikumpulkan atau diperoleh menggunakan kuesioner berisi pertanyaan tentang pelayanan kefarmasian terhadap lima variabel yang diberikan pada pasien yang menebus resep di Apotek Klinik Satkes Pusdokkes Mabes Polri, Data sekunder, yaitu data yang dikumpulkan untuk mendapatkan data yang mendukung penelitian dokumen-dokumen yang ada di tempat penelitian. Misalkan data yang diperoleh dari laporan tahunan pasien yang menebus resep di Apotek Klinik Satkes Pusdokkes Mabes Polri. Pengolahan data, yaitu data yang terkumpul diolah dan dianalisis dengan tahapan Editing data, Coding data, Processing data dan Cleaning data.

Instrumen dalam penelitian ini adalah lembar kuesioner yang berisi pertanyaan-pertanyaan yang berubungan dengan variabel-variabel penelitian yang harus dijawab responden. Sebelum dilakukan penelitian, maka dilakukan instrumen penelitian terlebih dahulu, yaitu dilakukan pengujian validitas dan realibilitas, dengan tujuan melihat kebenaran alat ukur dalam mengukur apa yang seharusnya diukur. Uji validitas dalam penelitian untuk memastikan apakah kuesioner yang akan dipakai untuk mengukur variabel penelitian valid atau tidak valid. Mengetahui validitas kuesioner 
maka dilakukan uji korelasi antara skor (nilai) tiaptiap item pertanyaan dengan nilai total kuesioner tersebut. Melakukan uji coba kuesioner tersebut pada sejumlah responden, disarankan jumlah responden uji coba minimal 30 responden, agar diperoleh distribusi nilai hasil pengukuran mendekati normal. Untuk keputusan uji validitas dinyatakan dengan nilai $\mathrm{r}$ dengan signifikansi $5 \%$ atau 0,05 , apabila nilai $r$ hitung $>0,361$ dinyatakan valid, sebaliknya jika nilai $r$ hitung $<0,361$ maka dinyatakan tidak valid. Dalam mencari nilai korelasi dalam penelitian ini menggunakan rumus Pearson product moment. Uji reliabilitas menunjukkan suatu alat ukur yang dapat dipercaya (dapat diandalkan) atau dengan kata lain menunjukkan sejauh mana hasil pengukuran tetep konsisten jika dapat dilakukan pengukuran dua kali atau lebih terhadap gejala yang sama. Uji reliabilitas hanya dilakukan pada pertanyaanpertanyaan yang sudah memenuhi uji validitas dan yang tidak memenuhi uji validitas maka tidak perlu diteruskan untuk uji realiabilitas. Nilai reliabilitas yang baik jika nilai Alpha Cronbach $\quad \geq 0,60$.

Analisa data penelitian ini menggunakan perangkat lunak program SPSS versi 18.0, berupa; Analisa univariat, yaitu analisis yang bertujuan untuk melihat variabel secara deskriptif, baik variabel dependen maupun variabel independen yang datanya disajikan dalam bentuk tabel distribusi frekuensi. Analisis statistik deskriptif pada demografi pasien yang digunakan sebagai variabel independent (bebas) meliputi: umur, jenis kelamin, pendidikan dan pekerjaan. Sedangkan variabel dependen (terikat) yaitu; lima dimensi kualitas pelayanan yang meliputi; kehandalan (reability), daya tanggap (responsiveness), Jaminan (assurance), bukti langsung (tangibles), empati (empathy) yang menghasilkan kepuasan pasien dan analisa bivariat, yaitu untuk menjelaskan dan menguji hubungan antara variabel dependen dengan variabel independen. Uji statistik yang digunakan adalah $\mathrm{Chi}$ square dengan derajat kepercayaan 95\% atau $\alpha=5 \%$ atau 0,05. Pengujian tersebut dapat diketahui ada atau tidaknya hubungan antara variabel independen dengan variabel dependen, dengan pengambilan keputusan apabila $\mathrm{p}$ value $<\alpha$, Ho ditolak, artinya ada hubungan yang signifikan dan sebaliknya apabila $\mathrm{p}$ value $>\alpha$, Ho diterima, artinya tidak ada hubungan yang signifikan.

Analisa tingkat kepuasan pada penelitian ini menggunakan skor persentase dalam skala likert, dimana responden menjawab quesioner dan jawaban tersebut diberi bobot nilai (Tabel 1)

Tabel 1. Bobot Nilai Kepuasan Responden Menurut Skala Likert

\begin{tabular}{|l|c|l|}
\hline No. & Skor & Jawaban Responden \\
\hline 1 & 5 & Sangat Puas \\
\hline 2 & 4 & Puas \\
\hline 3 & 3 & Cukup Puas \\
\hline 4 & 2 & Tidak Puas \\
\hline 5 & 1 & Sangat Tidak Puas \\
\hline
\end{tabular}

menurut Skala Likert dalam pengukuran tingkat kepuasan dapat ditunjukkan pada Tabel 2 sebagai berikut:

Tabel 2 Kriteria Interprentasi Persentase Skor menurut Skala Likert

\begin{tabular}{|l|l|l|}
\hline No. & $\begin{array}{c}\text { Angka } \\
\text { Persentase } \\
\text { Jumlah Skor }\end{array}$ & Jawaban \\
\hline 1 & $81 \%-100 \%$ & Sangat Puas \\
\hline 2 & $61 \%-80 \%$ & Puas \\
\hline 3 & $41 \%-60 \%$ & Cukup Puas \\
\hline 4 & $21 \%-40 \%$ & Tidak Puas \\
\hline 5 & $0 \%-20 \%$ & $\begin{array}{l}\text { Sangat Tidak } \\
\text { Puas }\end{array}$ \\
\hline
\end{tabular}

(Sumber: Susi Novaryatiin, 2018: 22 - 26)

\section{HASIL DAN PEMBAHASAN}

\section{Analisis Univariat}

Gambaran tentang demografi responden dalam penelitian ini meliputi umur, jenis kelamin, pendidikan terakhir dan pekerjaan yang dapat dilihat pada tabel 3. sebagai berikut:

Tabel 3 Gambaran Demografi Responden

\begin{tabular}{|c|c|c|c|c|}
\hline Demografi & Kategori & Frekuensi & $(\%)$ & Total \\
\hline \multirow[t]{4}{*}{ Umur } & $17-27$ th & 48 & 17,7 & \multirow{4}{*}{271} \\
\hline & $28-38$ th & 38 & 14,0 & \\
\hline & $39-49$ th & 85 & 31,4 & \\
\hline & $>49$ th & 100 & 36,9 & \\
\hline \multirow[t]{2}{*}{$\begin{array}{l}\text { Jenis } \\
\text { Kelamin }\end{array}$} & Laki-Laki & 153 & 56,5 & \multirow[t]{2}{*}{271} \\
\hline & Perempuan & 118 & 43,5 & \\
\hline \multirow[t]{3}{*}{ Pendidikan } & SD & 3 & 1,1 & \multirow{3}{*}{271} \\
\hline & SMP & 7 & 2,6 & \\
\hline & SMA & 116 & 42,8 & \\
\hline
\end{tabular}




\begin{tabular}{|c|c|c|c|c|}
\hline & SARJANA & 145 & 53,5 & \\
\hline Pekerjaan & $\begin{array}{l}\text { Ibu Rumah } \\
\text { Tangga }\end{array}$ & 1 & 0,4 & \multirow{4}{*}{271} \\
\hline & PNS & 148 & 54,6 & \\
\hline & POLISI & 109 & 40,2 & \\
\hline & Lainnya & 13 & 4,8 & \\
\hline
\end{tabular}

Sumber: Data Primer dan Diolah SPSS Tahun 2019

\section{Berdasarkan tabel diatas, dari total}

271 Responden yang mengisi kuesioner berdasarkan identitas pasien yang berobat dan menebus obat berdasarkan resep di Apotek Klinik Satkes Pusdokkes Mabes Polri, demografi mayoritas responden dengan kategori umur >49 tahun sebanyak 100 orang dengan persentase sebesar 36,9\%. Hal ini dikarenakan responden pada kategori umur tersebut rentan terhadap penyakit dan kualitas hidup menurun atau penurunan daya tahan tubuh/kesehatan, sehingga kemungkinan untuk jatuh sakit atau terkena penyakit dan membutuhkan pengobatan yang besar. Selain itu dalam usia tersebut, selama dalam proses penelitian pasien bersedia untuk dijadikan responden dalam menjawab pertanyaan-pertanyaan yang dibutuhkan peneliti walaupun responden membutuhkan pertolongan untuk membacakan kuesioner tersebut pada peneliti.

Jenis kelamin terbanyak pada kategori lakilaki sebanyak 153 orang dengan persentase sebesar $56,5 \%$. Hal ini sejalan dengan jumlah yang berobat tahun sebelumnya kategori jenis kelamin laki-laki 56,3\% lebih banyak dibanding perempuan 43,8\% di Klinik Satkes Pusdokkes Mabes Polri. Selain itu, selama penelitian responden jenis kelamin laki-laki lebih banyak bersedia untuk menjadi responden atau mengisi kuesioner daripada jenis kelamin perempuan. Berdasarkan studi yang dilakukan Standford University menyatakan bahwa perempuan memiliki sistem imun atau kekebalan tubuh yang lebih tinggi diandingkan laki-laki. Hal ini dikarenakan adanya hormon esterogen yang berfungsi untuk meningkat kemampuan melawan virus. Oleh sebab itu kategori jenis kelamin laki-laki lebih mudah terkena penyakit daripada perempuan. (Irine Wibowo. 2018)

Untuk kategori pendidikan, mayoritas terbanyak berpendidikan Sarjana sebanyak 145 orang dengan persentase $53,5 \%$. Menurut Iswanto (2015) menjelaskan bahwa semakin tinggi tingkat pendidikan, maka akan semakin sadar pentingnya kesehatan, artinya tingkat pendidikan semakin tinggi apabila sakit, akan lebih cepat ditangani dengan berobat ke dokter dibandingkan dengan tingkat pendidikan yang lebih rendah, dimana pengetahuan yang dimiliki sangat minim tentang kesehatan, sehingga akan memilih untuk tidak berobat ke dokter selama sakit tersebut masih dapat ditahan oleh dirinya sendiri.

Untuk kategori Pekerjaan sebagian besar berprofesi pada kategori PNS sebanyak 148 orang dengan persentase $54,6 \%$. Hal ini dikarenakan selama penelitian PNS di Polri lebih banyak bersedia menjadi reponden untuk mengisi kuesioner. Selain itu, penelitian lain yang dilakukan oleh Ade Octavia, dkk (2012) tentang analisis kepuasan pasien rawat inap Bangsal Jantung di RSUD Raden Mattaher Jambi yang menunjukkan mayoritas jumlah responden pada pekerjaan PNS sebesar 37,14\%.

Penelitian ini analisis tingkat kepuasan pasien diukur berdasarkan lima dimensi kualitas pelayanan, yaitu kehandalan (reability), daya tanggap (responsiveness), Jaminan (assurance), bukti langsung (tangibles) dan empaty (empathy).

Tabel 4. Dimensi Kehandalan (Reliability)

\begin{tabular}{|c|c|c|c|}
\hline Pernyataan & Skor & $\begin{array}{c}\text { Persentase } \\
(\%)\end{array}$ & $\begin{array}{c}\text { Kriteria } \\
\text { Interpretasi }\end{array}$ \\
\hline $\begin{array}{l}\text { Petugas apotek } \\
\text { melayani pasien } \\
\text { dengan ramah dan } \\
\text { tersenyum }\end{array}$ & $\begin{array}{c}1.04 \\
0\end{array}$ & 76,8 & Puas \\
\hline $\begin{array}{l}\text { Petugas apotek } \\
\text { memberikan } \\
\text { penjelasan tentang } \\
\text { aturan dan cara } \\
\text { pakai obat yang } \\
\text { diberikan sesuai } \\
\text { resep terhadap } \\
\text { pasien }\end{array}$ & $\begin{array}{c}1.03 \\
8\end{array}$ & 76,6 & Puas \\
\hline $\begin{array}{lr}\text { Obat } & \text { yang } \\
\text { diresepkan } & \text { selalu } \\
\text { tersedia di apotek }\end{array}$ & 888 & 65,5 & Puas \\
\hline $\begin{array}{lr}\text { Kemasan } & \text { obat } \\
\text { yang } & \text { diterima } \\
\text { dalam } & \text { keadaaan } \\
\text { baik } & \end{array}$ & $\begin{array}{c}1.00 \\
3\end{array}$ & 74,0 & Puas \\
\hline Rata-Rata & 992 & 73,2 & Puas \\
\hline
\end{tabular}

Sumber: Data Primer dan Diolah SPSS Tahun 2019

Hasil pengamagan di atas ditinjau dari beberapa pernyataan dimensi kehandalan, kepuasan tertinggi pada pernyataan petugas apotek 
melayani pasien dengan ramah dan tersenyum dengan jumlah skor 1.040 (76,8\%). Selain itu disusul petugas dalam memberikan penjelasan tentang aturan dan cara pakai obat yang diberikan sesuai resep dengan jumlah skor sebesar 1.038 (76,6\%), kemasan obat yang diterima dalam kondisi baik dengan jumlah skor sebesar 1.003 $(74,0 \%)$ dan obat yang selalu tersedia di apotek dengan jumlah skor sebesar $888 \quad(65,5 \%)$. Sedangkan dari semua item pernyataan didapatkan rata- rata skor sebesar $992(73,2 \%)$ dengan hasil interprestasi puas, yang artinya pasien atau responden puas terhadap dimensi kehandalan pada pelayanan Kefarmasian di Apotek Klinik Satkes Pusdokkes Mabes Polri, yang berarti kemampuan dalam memberikan pelayanan secara akurat dan terpercaya dalam pelayanan kefarmasian di Apotek Klinik Satkes Pusdokkes Mabes Polri kepada responden baik,

Berdasarkan Peraturan Menteri Kesehatan (Permenkes) Nomor 73 tahun 2016 tentang Standar Pelayanan Kefarmasian di Apotek, penyelenggaraan pelayanan kefarmasian yang diberikan kepada pasien harus didukung pada sumber daya kefarmasian terutama dalam sikap petugas apotek terhadap pelayanan pada pasien. Selain itu, dalam pelayanan kefarmasian klinik, petugas apotek mampu dalam mengkaji resep sesuai farmasetik, misalnya bentuk dan kompatibilitas obat (ketercampuran obat) atau interaksi obat pada obat atau makanan dan minuman, serta pertimbangan klinis, yang meliputi indikasi dan dosis obat, cara dan lama penggunaan obat. Selain pengkajian resep, apotek juga harus mampu dalam mengelola sediaan farmasi, alat kesehatan dan bahan medis habis pakai, terutama dalam hal perencanaan, pengadaan, penerimaan dan penyimpanan. Karena dengan adanya perencanaan, pengadaan dan pengendalian yang baik untuk sediaan farmasi terutama obat, yang diresepkan dokter selalu tersedia di apotek. Sedangkan untuk penyimpanan juga harus diperhatikan karena berkaitan dengan kualitas keamanan dan kontaminasi obat sehingga obat yang diberikan kepada pasien dalam keadaan kemasan yang baik atau tidak rusak.

Tabel 5 Dimensi Daya Tanggap (Responsiveness)

\begin{tabular}{|c|c|c|c|}
\hline Pernyataan & Skor & $\begin{array}{c}\text { Persentase } \\
(\%)\end{array}$ & $\begin{array}{l}\text { Kriteria } \\
\text { Interpretasi }\end{array}$ \\
\hline $\begin{array}{l}\text { Pelayanan resep } \\
\text { dilakukan dengan } \\
\text { cepat: Racikan } \leq \\
60 \text { menit } \\
\text { Non racikan } \leq 30 \\
\text { menit }\end{array}$ & 982 & 72,5 & Puas \\
\hline $\begin{array}{l}\text { Petugas apotek } \\
\text { memberikan } \\
\text { informasi yang } \\
\text { jelas dan tepat } \\
\text { serta mudah } \\
\text { dimengerti } \\
\text { pasien }\end{array}$ & 992 & 73,2 & Puas \\
\hline $\begin{array}{l}\text { Petugas apotek } \\
\text { tepat memberikan } \\
\text { obat kepada } \\
\text { pasien yang } \\
\text { menebus obat } \\
\text { tersebut. }\end{array}$ & 1.092 & 80,6 & $\begin{array}{l}\text { Sangat } \\
\text { Puas }\end{array}$ \\
\hline \begin{tabular}{l} 
Petugas apotek \\
melayani keluhan \\
\multicolumn{1}{c}{ pasien } \\
dan memberikan \\
solusi atau \\
penyelesaian \\
terhadap keluhan \\
tersebut.
\end{tabular} & 878 & 64,8 & Puas \\
\hline Rata-Rata & 986 & 72,8 & Puas \\
\hline
\end{tabular}

Sumber: Data Primer dan Diolah SPSS Tahun 2019

Pada dimensi daya tanggap tabel 5, didapat hasil interpretasi sangat puas pada pernyataan petugas apotek tepat memberikan obat kepada pasien yang menebus obat tersebut dengan jumlah skor sebesar $1.092(80,6 \%)$. Disusul dengan interpretasi puas pada pernyataan petugas apotek memberikan informasi yang jelas dan tepat serta mudah dimengerti pasien dengan jumlah skor 992 $(73,2 \%)$, kemudian pelayanan resep dilakukan dengan cepat dengan jumlah skor $982(72,5 \%)$ dan petugas apotek melayani keluhan pasien dan memberikan solusi atau penyelesaian dengan jumlah skor sebesar 878 (64,8\%). Tetapi dengan hasil rata-rata pada semua item pernyataan tersebut yang didapat jumlah skor sebesar $986(72,8 \%)$ dengan hasi interpretasi puas. Dengan hasil tersebut dinyatakan responden atau pasien merasa puas dengan dimensi daya tanggap (responsiveness) pada pelayanan kefarmasian di Apotek Klinik Satkes Pusdokkes Mabes Polri, yang berarti pada dimensi ini pelayanan yang 
diberikan dalam membantu dan memberikan pelayanan yang cepat, tepat atau kesigapan kepada pasien dan penyampaian informasi yang jelas pada pelayanan kefarmasian di Apotek Klinik Satkes Pusdokkes Mabes Polri pada responden atau pasien adalah baik.

Berdasarkan Peraturan Menteri Kesehatan Nomor 73 tahun 2016 tentang Standar Pelayanan Kefarmasian di Apotek, terutama mengenai pelayanan farmasi klinik yang menjelaskan setelah penyiapan obat dilakukan pengecekan kembali mengenai penulisan nama pasien pada etiket, cara penggunaan jenis dan jumlah obat sebelum diberikan kepada pasien, selain itu memastikan bahwa yang menerima obat tersebut adalah pasien atau keluarganya yang tepat dan hendaklah dilakukan dengan cara yang baik, mengingat pasien dalam kondisi tidak sehat atau emosinya tidak stabil. Ketika obat diberikan kepada pasien, diberikan Pelayanan Informasi Obat (PIO) di apotek, anatara lain; menjawab pertanyaan baik secara lisan maupun tulisan, berupa keluhan dan memberikan solusi atau penyelesaian dan memberikan informasi yang jelas dan dimengerti pasien meliputi dosis, bentuk sediaan, rute, metode pemberian, farmakokinetik dan farmakologi, efek samping, interaksi dan lainlain yang dapat langsung mempengaruhi obat tersebut.

Tabel 6 Dimensi Jaminan (Assurance)

\begin{tabular}{|c|c|c|c|}
\hline Pernyataan & Skor & $\begin{array}{l}\text { Persentas } \\
\mathrm{e} \\
(\%)\end{array}$ & $\begin{array}{l}\text { Kriteria } \\
\text { Interpret } \\
\text { asi }\end{array}$ \\
\hline $\begin{array}{l}\text { Pengetahuan petugas } \\
\text { apotek } \\
\text { mengenai obat- } \\
\text { obatan terhadap resep } \\
\text { yang diberikan }\end{array}$ & 941 & 69,4 & Puas \\
\hline $\begin{array}{l}\text { Pasien merasa } \\
\text { obat yang } \\
\text { diberikan tepat } \\
\text { dan sesuai dengan } \\
\text { resep }\end{array}$ & 954 & 70,4 & Puas \\
\hline $\begin{array}{l}\text { Petugas apotek } \\
\text { sopan dan santun serta } \\
\text { rapi } \quad \text { terhadap } \\
\text { pelayanan obat. }\end{array}$ & $\begin{array}{l}1.09 \\
0\end{array}$ & 80,4 & Puas \\
\hline \begin{tabular}{lc}
\multicolumn{2}{l}{ Petugas apotek } \\
tepat & dalam \\
membaca & resep \\
dokter & yang \\
diberikan pasien
\end{tabular} & 940 & 69,4 & Puas \\
\hline Rata-Rata & 981 & 72,4 & Puas \\
\hline
\end{tabular}

Sumber: Data Primer dan diolah SPSS Tahun 2019
Untuk dimensi jaminan, berdasarkan tabel 6 jumlah skor tertinggi terdapat pada pernyataan petugas apotek dan santun serta rapi terhadap pelayanan obat pada pasien dengan jumlah skor $1.090(80,4 \%)$, disusul pernyataan pasien merasa obat yang diberikan tepat dan sesuai resep dengan jumlah skor 954 (70,4\%), kemudian pengetahuan petugas apotek mengenai obat-obatan terhadap resep yang diberikan serta petugas aptek tepat dalam membaca resep dokter yang diberikan pasien dengan jumlah skor 941 dan 940 (69,4\%). Untuk hasil rata-rata semua pernyataan didapatkan jumlah skor $981(72,4 \%)$ dengan hasil interpretasi puas. Dengan hasil tersebut responden atau pasien merasa puas untuk dimensi jaminan (assurance) pada pelayanan kefarmasian di Apotek Klinik Satkes Pusdokkes Mabes Polri, yang berarti pada dimensi ini terjamin mutu obat yang diserahkan kepada pasien sesuai dengan yang tertulis oleh dokter dan memberikan rasa percaya dan keyakinan kepada pasien pada pelayanan kefarmasian yang diberikan adalah baik.

Menurut Peraturan Menteri Kesehatan Nomor 73 tahun 2016 tentang Standar Pelayanan Kefarmasian di Apotek, mengenai pelayanan farmasi klinik bahwa pelaksanaan dimulai dari pegkajian dan pelayanan resep, dispensing, Pelayanan Informasi Obat (PIO), Konseling, Pemantauan Terapi Obat (PTO) dan sampai Monitoring Efek Samping Obat (MESO) semua tersebut harus terjamin kebenarannya dan baik dalam pelaksanaannya, sehingga pelayanan yang diberikan terjamin kualitas kepada pasien. Selain itu, peraturan tersebut juga mengatur mengenai sumber daya kefarmasian terutama tenaga kefarmasian untuk harus terus meningkatkan pengetahuan, sikap dan keterampilan profesi melalui pendidikan berkelanjutan

Tabel 7 Dimensi Bukti Langsung (Tangibles)

\begin{tabular}{|l|l|c|c|}
\hline Pernyataan & Skor & $\begin{array}{c}\text { Persentase } \\
(\%)\end{array}$ & $\begin{array}{c}\text { Kriteria } \\
\text { Interpretasi }\end{array}$ \\
\hline $\begin{array}{l}\text { Ruangan } \\
\text { apotek } \\
\text { terliha rapi } \\
\text { dan bersih }\end{array}$ & 1.061 & 78,3 & Puas \\
\hline
\end{tabular}




\begin{tabular}{|c|c|c|c|}
\hline Pernyataan & Skor & $\begin{array}{c}\text { Persentase } \\
(\%)\end{array}$ & $\begin{array}{l}\text { Kriteria } \\
\text { Interpretasi }\end{array}$ \\
\hline $\begin{array}{l}\text { Petugas apotek } \\
\text { berpenampilan } \\
\text { sopan, bersih } \\
\text { dan rapi }\end{array}$ & 1.067 & 78,7 & Puas \\
\hline $\begin{array}{ll}\text { Ruang } & \text { tunggu } \\
\text { pasien } & \text { apotek } \\
\text { nyaman } & \\
\end{array}$ & 985 & 72,7 & Puas \\
\hline $\begin{array}{l}\text { Penataan obat di } \\
\text { apotek terlihat } \\
\text { bersih dan rapi }\end{array}$ & 1.036 & 76,5 & Puas \\
\hline Rata-Rata & 1.037 & 76,5 & Puas \\
\hline
\end{tabular}

Sumber: Data Primer dan Diolah SPSS Tahun 2019

Berdasarkan data dimensi tangibles diperoleh hasil bahwa nilai kepuasan paling tinggi terdapat pada pernyataan petugas apotek berpenampilan sopan, bersih dan rapi dengan jumlah skor $1.067(78,7 \%)$, disusul dengan pernyataan ruangan apotek terlihat rapi dengan jumlah skor $1.036(76,5 \%)$ dan ruang tunggu pasien apotek nyaman dengan jumlah skor $985(72,7 \%)$ dengan hasil interpretasi puas. Untuk semua item pernyataan rata-rata yang didapatkan jumlah skor 1.037 dengan jumlah persentase sebesar $76,5 \%$ dengan hasil interpretasi puas, yang artinya pasien atau responden merasa puas terhadap dimensi bukti langsung (tangibles) pada pelayanan kefarmasian di Apotek Klinik Satkes Pusdokkes Mabes Polri, yang berarti sarana dan prasarana fisik berupa; kebersihan, kenyamanan tempat serta kerapian dan kebersihan penampilan petugas farmasi serta penataan obat di Apotek Klinik Satkes Pusdokkes Mabes Polri adalah baik.

Menurut Peraturan Menteri Kesehatan Nomor 73 tahun 2016 tentang Standar Pelayanan Kefarmasian di Apotek harus memiliki sarana dan parasarana yang baik dan memadai dalam hal kualitas dan kuantitas agar dapat menunjang fungsi dan pelayanan kefarmasian seperti; ruang tunggu yang nyaman bagi pasien, tempat untuk menerima resep dan memberikan obat. Selain sarana dan prasarana, Permenkes juga mengatur tentang sikap, kebersihan dan kerapian pada petugas apotek agar maksimal dalam memberikan pelayanan kefarmasian yang diberikan kepada pasien.
Tabel 8 Dimensi Empati (Empathy)

\begin{tabular}{|l|c|c|c|}
\hline \multicolumn{1}{|c|}{ Pernyataan } & Skor & $\begin{array}{c}\text { Persentase } \\
(\%)\end{array}$ & $\begin{array}{c}\text { Kriteria } \\
\text { Interpretasi }\end{array}$ \\
\hline $\begin{array}{l}\text { Petugas apotek } \\
\text { memberikan } \\
\text { perhatian } \\
\text { terhadap } \\
\text { keluhan yang } \\
\text { sama dan tulus } \\
\text { kepada setiap } \\
\text { pasien }\end{array}$ & 913 & 67,4 & Puas \\
\hline $\begin{array}{l}\text { Petugas apotek } \\
\text { memberikan } \\
\text { pelayanan } \\
\text { kepada setiap } \\
\text { pasien tanpa } \\
\text { memandang } \\
\text { status sosial }\end{array}$ & 894 & 66,0 & Puas \\
\hline $\begin{array}{l}\text { Pasien merasa } \\
\text { nyaman selama } \\
\text { menunggu obat }\end{array}$ & 975 & 72,0 & Puas \\
\hline $\begin{array}{l}\text { Petugas apotek } \\
\text { mampu } \\
\text { berkomunikasi } \\
\text { baik dengan } \\
\text { pasien. }\end{array}$ & 1.088 & 80,3 & Puas \\
\hline \multicolumn{1}{|c|}{ Rata-Rata } & $\mathbf{9 6 8}$ & $\mathbf{7 1 , 4}$ & Puas \\
\hline
\end{tabular}

Sumber: Data Primer dan Diolah SPSS Tahun 2019

Berdasarkan dimensi Emphathy diperoleh hasil bahwa nilai kepuasan tinggi terdapat pada pernyataan petugas apotek mampu dan bersih dengan jumlah skor $1.061(78,3 \%)$, kemudian pernyataan penataan obat di apotek terlihat bersih dan berkomunikasi baik dengan pasien yang berjumlah skor 1.088 (80,3\%). Kemudian disusul pernyataan pasien merasa nyaman selama menunggu obat dengan jumlah skor 975 $(72,0 \%)$, lalu petugas apotek memberikan perhatian terhadap keluhan yang sama dan tulus kepada pasien dan petugas apotek memberikan pelayanan kepada pasien tanpa memandang status sosial dengan masingmasing jumlah skor $913(67,4 \%)$ dan 894 (66,0\%). sedangkan rata-rata pada semua item pernyataan tersebut didapatkan jumlah skor 968 dengan persentase $71,4 \%$ yang hasil interpretasinya puas. Dengan hasil tersebut, pasien merasa puas pada dimensi empati (empathy) untuk pelayanan kefarmasian di Apotek Klinik Satkes Pusdokkes Mabes Polri, yang berarti pada dimensi ini Apotek Klinik Satkes Pusdokkes Mabes Polri memberikan pelayanan dengan perhatian khusus terhadap pasien, mulai dari keluhan hingga pelayanan 
kepada semua pasien tanpa memandang status sosial dengan tulus adalah baik.

Menurut Peraturan Pemerintah Republik Indonesia Nomor 51 tahun 2009 tentang pekerjaan kefarmasian bahwa tenaga teknis kefarmasian harus memberikan perlakukan yang sama dengan tidak membedakan suku, bangsa, agama, status sosial dan ras.

\section{Analisis Bivariat}

Tabel 9 Hasil Analisis Hubungan Umur Dengan Kepuasan Pasien

\begin{tabular}{|c|c|c|}
\hline \multirow[t]{2}{*}{ Umur (th) } & \multicolumn{2}{|c|}{ Total } \\
\hline & $\mathrm{n}$ & $\%$ \\
\hline $17-27$ & 48 & 17,7 \\
\hline $28-38$ & 38 & 14,0 \\
\hline $39-49$ & 85 & 31,4 \\
\hline$>49$ & 100 & 36,9 \\
\hline Jumlah & 271 & 100 \\
\hline
\end{tabular}

Sumber: Data Primer dan Diolah SPSS Tahun 2019

Berdasarkan tabel 9 menunjukkan hasil analisa setelah di uji statistik dengan uji Chi- Square, diperoleh $p$-value $0,016<\alpha=0,05$ dengan hasil Ho ditolak, yang artinya ada hubungan yang bermakna atau signifikan antara umur dengan kepuasan pasien pada pelayanan kefarmasian di Apotek Klinik Satkes Pusdokkes Mabes Polri. Menurut Loundon \& Bitta (1998) menyatakan bahwa semakin tua usia seseorang maka akan memiliki harapan yang lebih rendah dan cenderung merasa puas dibandingkan dengan seseorang yang usianya lebih muda.

Tabel 10. Hasil Analisis Hubungan Jenis Kelamin Dengan Kepuasan Pasien

\begin{tabular}{|c|c|c|}
\hline \multirow{2}{*}{ Jenis Kelamin } & \multicolumn{2}{|c|}{ Total } \\
\cline { 2 - 3 } & n & \% \\
\hline Laki-Laki & 153 & 56,5 \\
\hline Perempuan & 118 & 43,5 \\
\hline Jumlah & $\mathbf{2 7 1}$ & $\mathbf{1 0 0}$ \\
\hline
\end{tabular}

Sumber: Data Primer dan Data diolah SPSS Tahun 2019

Pada tabel 10 menunjukkan hasil analisa setelah di uji statistik dengan uji Chi-Square, diperoleh $p$-value $=0,206>\alpha=0,05$, dengan hasil Ho diterima, yang artinya tidak ada hubungan yang signifikan atau bermakna antara jenis kelamin dengan kepuasan pasien pada pelayanan kefarmasian di Apotek Klinik Satkes Pusdokkes Mabes Polri. Hal ini sejalan dengan jurnal Arif Kuriawan dan Arih Diyaning Intisari (2012), tentang pengaruh demografi pasien terhadap indeks kepuasan masyarakat tentang pelayanan rawat jalan Puskesmas Banyumas, yang menunjukkan tidak adanya hubungan yang bermakna antara jenis kelamin dengan tingkat kepuasan.

Tabel 11 Hasil Analisis Hubungan Pendidikan Dengan Kepuasan Pasien

\begin{tabular}{|l|c|c|}
\hline \multirow{2}{*}{ Pendidikan } & \multicolumn{2}{|c|}{ Total } \\
\cline { 2 - 3 } & $\mathbf{n}$ & $\mathbf{\%}$ \\
\hline SD & 3 & 1,1 \\
\hline SMP & 7 & 2,6 \\
\hline SMA & 116 & 42,8 \\
\hline SARJANA & 145 & 53,5 \\
\hline Jumlah & $\mathbf{2 7 1}$ & $\mathbf{1 0 0}$ \\
\hline
\end{tabular}

Sumber: Data Primer dan Data diolah SPSS Tahun 2019

Pada tabel 11 menunjukkan hasil analisa setelah di uji statistik dengan uji Chi-Square, diperoleh $p$-value $=0,000<\alpha=0,05$, dengan hasil Ho ditolak, yang artinya ada hubungan yang signifikan atau bermakna antara pendidikan dengan kepuasan pasien pada pelayanan kefarmasian di Apotek Klinik Satkes Pusdokkes Mabes Polri. Hal ini sejalan dengan hasil penelitian Raudahatul Ulfa (2012), yang menyatakan bahwa pendidikan memiliki hubungan dengan loyalitas pelanggan dan menyatakan bahwa semakin tinggi tingkat pendidikan seseorang maka akan mempengaruhi pola pikir yang nantinya berdampak pada tingkat kepuasan (Robert Kreitner, Angelo Kinicki, 2003).

Tabel 12 Hasil Analisis Hubungan Pekerjaan Dengan Kepuasan Pasien

\begin{tabular}{|c|c|c|}
\hline \multirow{2}{*}{ Pekerjaan } & \multicolumn{2}{|c|}{ Total } \\
\cline { 2 - 3 } & $\mathbf{n}$ & $\mathbf{\%}$ \\
\hline Ibu Rumah Tangga & 1 & 0,4 \\
\hline PNS & 148 & 54,6 \\
\hline Polisi & 109 & 40,2 \\
\hline Lainnya & 13 & 4,8 \\
\hline Jumlah & $\mathbf{2 7 1}$ & $\mathbf{1 0 0}$ \\
\hline
\end{tabular}

Sumber: Data Primer dan Data diolah SPSS Tahun 2019

Pada tabel 12 menunjukkan hasil analisa setelah di uji statistik dengan uji Chi-Square, diperoleh $p$ value $=0,815>\alpha=0,05$, Ho diterima, yang artinya tidak ada hubungan yang signifikan atau bermakna antara pekerjaan dengan kepuasan pasien pada pelayanan kefarmasian di Apotek Klinik Satkes Pusdopakakkes Mabes Polri. Hal ini dikarenakan meskipun status pekerjaannya bekerja atau tidak bekerja mereka tetap menggunakan layananan 
kesehatan di Apotek Klinik Satkes Pusdokkes Mabes Polri.

\section{KESIMPULAN}

Tingkat kepuasan pelayanan kefarmasian di Apotek Klinik Satkes Pusdokkes Mabes Polri dipengaruhi oleh 5 (lima) dimensi, yaitu kehandalan (reliability), daya tanggap (responsiveness), jaminan (assurance), bukti langsung (tangibles) dan empaty (empathy). Dari kelima dimensi tersebut, rata-rata merasakan responden merasa puas, tetapi yang paling tinggi tingkat kepuasan pasien dalam pelayanan kefarmasian dengan persentase terbesar adalah pada dimensi bukti langsung (tangibles) sebesar 76,5\%. Hasil analisa mengenai hubungan karakteristik pasien dengan tingkat kepuasan terhadap pelayanan kefarmasian, dimana ada hubungan yang bermakna antara umur dan pendidikan dengan kepuasan pasien pada pelayanan kefarmasian di Apotek Klinik Satkes Pusdokkes Mabes Polri, sebaliknya tidak ada hubungan yang bermakna antara pekerjaan dan jenis kelamin dengan kepuasan pasien pada pelayanan kefarmasian di Apotek Klinik Satkes Pusdokkes Mabes Polri.

\section{DAFTAR PUSTAKA}

1. A.A., Barata. (2006). Dasar-Dasar Pelayanan Prima. Jakarta: PT. Elex Media Komputindo.

2. Dianita, Puspita Septie, Elmiawati Latifah. (2017). Tingkat Kepuasan Pasien Terhadap Pelayanan Obat Di Apotek Wilayah Kecamatan Mertoyudan Kabupaten Magelang. Jurnal Farmasi Sains dan Praktis, Vol. III, No. 2.

3. Hadi, Ghina Nuraini. (2018). Hubungan Karakteristik Individu Terhadap Kepuasan Pasien Peserta BPJS Pada Pelayanan Kefarmasian Di Rumah Sakit Marinir Cilandak. Skripsi Institut Sains dan Teknologi Nasional. Jakarta

4. Hayaza, Yaseer Thariq. (2013). Analisis Kepuasan Pasien Terhadap Kualitas Pelayanan Kamar Obat Di Puskesmas Surabaya Utara. Jurnal Ilmiah Mahasiswa Universitas Surabaya Vol. 2 No. 2.

5. Helni. (2015). Tingkat Kepuasan Pasien Terhadap Pelayanan Apotek Di Kota Jambi. Jurnal Penelitian Universitas Jambi Seri Humaniora Vol 17, No. 2, Hal. 01-08.

6. Hidayati, Aulia Nur, dkk. (2014). Analisis Hubungan Karakteristik Pasien Dengan Kepuasan Pelayanan Rawat Jalan Semarang Eye Center (SEC) Rumah Sakit Islam Sultan Agung Semarang. Jurnal Kesehatan Masyarakat Vol. 1 Nomor 1.
7. Kurniawan, Arif dan Arih Diyaning I., (2012). Pengaruh Karakteristik Pasien Terhadap Indeks Kepuasan Masyarakat Tentang Pelayanan Rawat Jalan Puskesmas Banyumas. Jurnal Kesmasindo Mahasiswa Universitas Soedirman Volume 5 Nomor 2 hal. 169-179.

8. Mas'ud. (2009). Analisis Tingkat Kepuasan Pelanggan Terhadap Pelayanan Instalasi Farmasi Kimia Farma Jakarta Menggunakan Model Servqual (Studi Kasus Pada 3 Instalasi Farmasi). Jurnal Majalah Ilmu Kefarmasian. Vol. 6 No. 2.

9. Menteri Kesehatan Republik Indonesia. (2016). Peraturan Menteri Kesehatan Republik Indonesia Nomor 73 Tahun 2016 tentang Standar Pelayanan Kefarmasian di Apotek. Jakarta.

10. Novaryatin, Susi, Syahrida Dian Ardhany, \& Siti Aliyah. (Mei 2018). Tingkat Kepuasan Pasien Terhadap Pelayanan Kefarmasian Di RSUD Dr. Murjani Sampit. Borneo Journal of Pharmacy, Volume I Issue I, May 2018, Page 22-26.

11. Octavia, Ade, Suswitaroza dan Aulia Putri Anwar. (2012). Analisis Kepuasan Pasien Rawat Inap Bangsal Jantung Di RSUD Raden Mattaher Jambi. Jurnal DMJ UnJa, Vol 1 No. 1 JanuariMaret 2012.

12. Purba, Mufita. (2012). Hubungan Karakteristik Pasien Dengan Tingkat Kepuasan Terhadap Pelayanan Keperawatan Di Klinik Satuan Kesehatan Pusdokkes Mabes Polri Tahun 2011. Skripsi. Fakultas Ilmu Kesehatan Universitas Respati Indonesia. Jakarta.

13. S. Armansyah. (2014). Hubungan Tingkat Kepuasan Pasien Rawat Jalan Pada Pelayanan Kefarmasian di RSUD Pasar Rebo Periode MeiJuni 2014. Skripsi. FMIPA. Institut Sains dan Teknologi Nasional. Jakarta.

14. Tjiptono, Fandy. (2005). Service, quality and satisfaction. Yogyakarta: Andi.

15. Utama, S. (2003). Memahami Fenomena Kepuasan Pasien Rumah Sakit Medan. FKM USU.

16. Yulia, Prima Roza, Lukman M. Baga, \& Setiadi Djohar. (September 2016). Kepuasan Konsumen Terhadap Pelayanan Apotek Dan Tingkat Pengetahuan Konsumen Mengenai Standar Pelayanan Kefarmasian Yang Berlaku (Studi Kasus Di Kota Depok). Jurnal Aplikasi Bisnis dan Manajemen, Vol. 2 No. 3.

17. Yunevy, E. (2013). Analisis Kepuasan Berdasarkan Persepsi dan Harapan Pasien di Puskesmas Medokan Ayu Surabaya. Jurnal Administrasi Kesehatan Indonesia. Surabaya. 
